\title{
Supporting Community Pharmacies with Implementation of a Web-Based Medication Management Application
} \author{
Christopher M. Shea ${ }^{1}$ \\ ${ }^{1}$ Department of Health Policy and Management, University of North \\ Carolina Gillings School of Global Public Health, Chapel Hill, \\ North Carolina, United States \\ ${ }^{2}$ Department of Clinical Pharmacy and Translational Science, \\ University of Tennessee Health Science Center, Memphis, \\ Tennessee, United States \\ 3 Division of Practice Advancement and Clinical Education, University \\ of North Carolina Eshelman School of Pharmacy, Chapel Hill, \\ North Carolina, United States \\ ${ }^{4}$ Community Pharmacy Enhanced Services Network, Community \\ Care of North Carolina, Raleigh, North Carolina, United States
}

Kea Turner ${ }^{1}$ Chelsea Renfro ${ }^{2}$ Stefanie Ferreri ${ }^{3} \quad$ Kim Roberts $^{4}$ Trista Pfeiffenberger ${ }^{4}$

\author{
Address for correspondence Kea Turner, PhD, MPH, MA, Department \\ of Health Policy and Management, University of North Carolina at \\ Chapel Hill, 1104F McGavran Greenburg Hall, CB 7411, Chapel Hill, NC \\ 27599-7411, United States (e-mail: keat@email.unc.edu).
}

Appl Clin Inform 2018;9:391-402.

\author{
Abstract \\ Keyvords \\ - community \\ pharmacy \\ - pharmacy \\ information systems \\ - implementation and \\ deployment \\ - medication \\ management \\ - clinical \\ documentation \\ - implementation \\ science \\ - medication \\ management \\ application \\ - documentation
}

Objective Community pharmacists' role in clinical care is expanding in the United States and information systems are needed that extend beyond a dispensing workflow. As pharmacies adopt new systems, implementation support will be needed. This study identifies the barriers and facilitators experienced by community pharmacies in implementing a Web-based medication management application and describes the implementation strategies used to support these pharmacies.

Methods Semistructured interviews were conducted with 28 program and research staff that provides support to community pharmacies participating in a statewide pharmacy network. Interviews were recorded, transcribed verbatim, and analyzed for themes using the Expert Recommendations for Implementing Change (ERIC).

Results Findings suggest that leadership support, clinical training, and computer literacy facilitated implementation, while lack of system integration, staff resistance to change, and provider reluctance to share data served as barriers. To overcome the barriers, implementation support was provided, such as assessing readiness for implementation, developing a standardized and interoperable care plan, and audit and feedback of documentation quality. Conclusion Participants used a wide array of strategies to support community pharmacies with implementation and tailored approaches to accommodate pharmacy-specific preferences. Most of the support was delivered preimplementation or in the early phase of implementation and by program or research staff rather than peerto-peer. Implementing new pharmacy information system requires a significant amount of implementation support to help end-users learn about program features, how to integrate the software into workflow, and how to optimize the software to improve patient care. Future research should identify which implementation strategies are associated with program performance. received

January 5, 2018

accepted after revision

April 8, 2018
Copyright (๐) 2018 Schattauer 


\section{Background and Significance}

Over the past decade, chronic illness and multimorbidity (i.e., the presence of two or more chronic conditions) have increased in the United States, and they are projected to continue increasing. ${ }^{1}$ Although many chronic diseases can be prevented, delayed, or managed, ${ }^{2}$ use of preventive services, compliance with medical recommendations, and medication adherence, are suboptimal. ${ }^{3-5}$ To improve chronic disease prevention and management, alternative payment models in the U.S. are beginning to integrate community pharmacists into teambased care arrangements. ${ }^{6-8}$ Community pharmacists-who have clinical training and are often more accessible to patients than other providers-can provide medication management and other clinical services to support chronic disease prevention and management. ${ }^{9-15}$ To perform these services most effectively, however, community pharmacists need access to patients' clinical data, such as notification when a patient is admitted to or discharged from the hospital, a complete list of medications at home and upon care transitions that is updated as close to real-time as possible across all prescribers, and laboratory values. ${ }^{16-19}$

Pharmacy management systems have been designed to align with a dispensing workflow and have only recently started to support community pharmacists' expanding role in clinical care. For example, many pharmacy management systems allow users to develop a prescription profile and history but may not include features that capture a patient's clinical data, such as a list of nonprescription medications, medications dispensed at other pharmacies, medications paid for with cash, hospital admissions, and laboratory values. ${ }^{16,20,21}$ Access to health care providers' electronic health record (EHR) systems and health information exchange (HIE) programs can enable community pharmacies to view these data. ${ }^{16,20,22}$ In fact, studies have shown that granting community pharmacists access to EHRs can support clinical services; however, implementing access to each EHR system individually can be challenging because community pharmacists work with many different providers. $^{22,23}$ Further, the pharmacy's management system may not interface with the providers' EHR, requiring pharmacies to print the patient's record and enter the information by hand into the pharmacy's system. ${ }^{24}$ HIEs may be a more feasible solution to providing data access across multiple provider settings; however, rules about the types of clinical data that can be shared with pharmacists vary across HIE programs. ${ }^{8,16,20,25}$ Studies examining community pharmacy participation in HIEs have reported barriers such as finding a software vendor that supports pharmacy connection to the HIE, delays in receipt of data, and costly user fees. ${ }^{22,26}$

In addition to clinical data access, community pharmacists participating in team-based care arrangements need to document clinical services to demonstrate evidence about service quality provided and track patient outcomes longitudinally. Studies have found that community pharmacies implementing new electronic documentation systems encounter barriers such as lack of time for documentation, limited training and low selfefficacy, and staff resistance to change. ${ }^{12,22,27-32}$ Additionally, pharmacies have reported difficulty with usability, lack of standardization across documentation systems, and lack of interoperability between the pharmacy's management system and other documentation systems. ${ }^{22,27,31,33}$ Pharmacies may, for example, document services in their pharmacy management system and also be required to document services in payer-specific, documentation software. ${ }^{27,33}$ Further, pharmacies participating in multiple, payer-supported medication management interventions may have to operate several documentation systems simultaneously and may have difficulty using systems that are designed for billing and episodic care to support longitudinal clinical care. ${ }^{33}$ To address these barriers, technology vendors are beginning to develop Web-based medication management applications that allow for documentation of clinical services, integration of clinical data, and tracking of patient outcomes. However, there is limited research on how to support community pharmacies with implementation of these systems.

\section{Objective}

To address this need, our study has two aims: (1) to identify the barriers and facilitators experienced by community pharmacies implementing a Web-based medication management application within a statewide network of community pharmacies; and (2) to describe the implementation strategies used to support these community pharmacies.

\section{Methods}

\section{Setting}

Approximately 275 community pharmacies are participating in the Community Pharmacy Enhanced Service Network (CPESN) in North Carolina (NC). NC-CPESN was established by Community Care of North Carolina (CCNC), which is the primary care case management program for NC Medicaid, and is designed for Medicaid and Medicare patients with multiple chronic conditions. ${ }^{6}$ CCNC consists of over 1,800 primary care practices across $\mathrm{NC}$ and has approximately 650 nurse or social work care managers providing intensive care management services to the highest risk chronically ill beneficiaries. ${ }^{6}$ NC-CPESN pharmacies have, on average, 80,000 encounters with chronically ill beneficiaries each month including 1,500 patients that receive an in-depth consultation with a pharmacist. ${ }^{34} \mathrm{NC}-\mathrm{CPESN}$ requires pharmacies to deliver a set of medication management services, establish a care plan, and be reimbursed based on a valuebased payment model. Any community pharmacy is eligible to participate in NC-CPESN as long as the pharmacy is willing to provide and document the required services in PHARMACeHOME-a Web-based, medication management application that captures patient health information from multiple sources including prescription history, diagnosis data, hospitalization data, immunization data, Medicaid claims data, and laboratory results. ${ }^{6,35}$ PHARMACeHOME also allows community pharmacies to record medication lists from various care settings, identify, track, and resolve drug therapy problems, and create summary notes. Pharmacists can share information about patients from PHARMACeHOME 
with providers (e.g., drug therapy problems, care plans) using a Web-based platform, the Provider Portal, while care managers could directly access PHARMACeHOME to view patient information. To be eligible for reimbursement, pharmacies were required to document a comprehensive medication review in PHARMACeHOME including a list of medications, a medication skills assessment, drug therapy problems, and a patient care plan. The required software for NC-CPESN participation changed in the third program year from PHARMACeHOME to the Pharmacist eCare Plan; however, the documentation requirements stayed the same. This change is described in more detail in the "Results" section.

To support PHARMACeHOME implementation, community pharmacies receive assistance from CCNC's 14 regional networks and central office, and research teams from two NC universities. CCNC's regional networks provide in-person training and technical assistance on PHARMACeHOME and implementation of clinical services. The central office personnel provide training by phone and via webinar on the NCCPESN program requirements and the available resources at CCNC (e.g., practice support staff to assist with developing relationships with medical practices, care management staff to comanage specific patients, etc.) and provide technical assistance when pharmacies have questions about program requirements. The research teams also provide in-person implementation support to participating pharmacies including workflow assessment, quality improvement support, and quality audits of documentation. The results section provides greater detail on the implementation support provided by each of these groups (e.g., CCNC regional staff, central staff, and the research team).

\section{Data Collection}

To examine how implementation support is delivered to NCCPESN pharmacies, we interviewed participants from each of the groups that deliver support: CCNC central office staff, CCNC network pharmacists, CCNC network care managers, and the research team ( - Table 1 ). We chose in-depth interviews rather than focus groups as our data collection method because we were interested in understanding staff members' individualized rather than shared approaches to providing implementation support. ${ }^{36}$ We used a semistructured, interview guide approach so that data collection was systematic for each participant (i.e., a similar set of questions were asked) but there was flexibility to ask additional probing questions to capture participants' unique insights. ${ }^{36}$ Twentyeight interviews were conducted from March to June 2016. Interviews lasted approximately 1 hour and were conducted over the phone to ensure that participants in any location throughout the state could participate.

\section{Recruitment and Participants}

We asked CCNC and research team staff to identify individuals who provide implementation support to NC-CPESN pharmacies. We emailed these individuals to request an interview about their experiences with delivering implementation support. We had three individuals decline to participate due to lack of time. Participants provided informed consent over the phone. The Institutional Review Board of the University of North Carolina at Chapel Hill approved this study (IRB \# 16-0530).

\section{Data Analysis}

Two research team members trained in qualitative methods facilitated the interviews (K.T. and C.S.). The interviews were audio-recorded and transcribed verbatim. We used the research objectives and the interview guide to generate a list of structural codes that were applied to each transcript. ${ }^{36}$ Two members of the research team (K.T. and C.S.) coded the transcripts using the Dedoose qualitative software (version 4.12 ) and met to discuss and resolve discrepancies in coding. After coding was complete, members of the research team (K.T. and C.S.) discussed the summary reports to generate emergent codes based on the qualitative data. ${ }^{36}$

Themes were organized using the Expert Recommendations for Implementing Change (ERIC), which identifies and defines categories of implementation strategies. ${ }^{37,38}$ Implementation strategies are defined as the "methods or techniques used to enhance the adoption, implementation, and sustainability of a clinical program or practice." ${ }^{39,40}$ The ERIC identifies six categories of implementation strategies but we focused on the four categories most relevant to this project: planning strategies, education strategies, restructure strategies, and quality-management strategies. To describe the implementation strategies identified in this article, we used Proctor et al's guidelines for specifying implementation

Table 1 Staff roles of interview participants $(N=28)$

\begin{tabular}{|l|l|}
\hline Staff role (Description of support provided to participating pharmacies) & Number of interviewees \\
\hline $\begin{array}{l}\text { CCNC central office staff (Provide support to all 14 networks and participating } \\
\text { pharmacies including training on program requirements, technical assistance, } \\
\text { and resources including access to PHARMACeHOME) }\end{array}$ & 6 \\
\hline $\begin{array}{l}\text { CCNC network pharmacist (Provide PHARMACeHOME-related training, } \\
\text { patient referrals, and training on how to implement clinical services }\end{array}$ & 12 \\
\hline $\begin{array}{l}\text { CCNC network care manager (Provide patient referrals and patient-specific } \\
\text { advice on clinical and social needs that impact medication use) }\end{array}$ & 5 \\
\hline $\begin{array}{l}\text { Research team (Provide support with workflow assessment, quality } \\
\text { improvement support, and quality audits of documentation) }\end{array}$ & 5 \\
\hline
\end{tabular}

Abbreviation: CCNC, Community Care of North Carolina. 
strategies, which provides guidance to researchers on how to report implementation strategies with enough detail that the study findings can be used by other researchers and practitioners. ${ }^{39}$ We provide an example of documentation for each implementation strategy.

\section{Results}

\section{Barriers to Using PHARMACeHOME}

While providing implementation support, participants gained insight into the barriers and facilitators that affected community pharmacies' use of PHARMACeHOME ( - Table 2). In terms of barriers, pharmacies encountered provider reluctance to share data, staff resistance to documentation, slow Internet connection, and lack of time for staff training. Participants explained that some providers were reluctant to share data, such as medication lists, with pharmacists due to concerns about privacy or because of lack of knowledge about pharmacist-led clinical services. Provider reluctance to share patient health information limited pharmacists' ability to develop an accurate medication list in PHARMACeHOME. Some pharmacies were able to overcome this barrier by developing relationships with providers (e.g., scheduling regular meetings). Additionally, some pharmacy staff did not see the value in documenting clinical services and as a result were resistant to using PHARMACeHOME. Some pharmacies also had difficulty logging on to PHARMACeHOME due to a slow Internet connection, particularly at peak times of usage (e.g., 8-10 a.m.). Because of the time it took to train staff on PHARMACeHOME, many pharmacies only trained 1 to 2 staff members and made them responsible for documentation, which often prevented services from being documented during the patient encounter.

Participants also reported PHARMACeHOME-design barriers including lack of PHARMACeHOME integration with other pharmacy management systems and lack of standardized

Table 2 Interview themes and illustrative quotations

\begin{tabular}{|c|c|c|}
\hline Themes & Definition & Illustrative quotation \\
\hline Facilitators & $\begin{array}{l}\text { Factors that assist community } \\
\text { pharmacies with PHARMACeHOME } \\
\text { implementation }\end{array}$ & $\begin{array}{l}\text { "When a pharmacy has a designated } \\
\text { staff member to assist with data entry in } \\
\text { PHARMACeHOME and the pharmacy's } \\
\text { other information systems it [imple- } \\
\text { mentation] goes a lot smoother" }\end{array}$ \\
\hline Barriers & $\begin{array}{l}\text { Factors that hinder PHARMACeHOME } \\
\text { implementation in community } \\
\text { pharmacies }\end{array}$ & $\begin{array}{l}\text { "Their [pharmacy management] } \\
\text { systems don't communicate with } \\
\text { PHARMACeHOME so we are requiring } \\
\text { them right now to double document. } \\
\text { That wastes a lot of time" }\end{array}$ \\
\hline $\begin{array}{l}\text { Assess for readiness and identify barriers } \\
\text { and facilitators }\end{array}$ & $\begin{array}{l}\text { Assess various factors within the } \\
\text { pharmacy to determine their readiness } \\
\text { for NC-CPESN and barriers and facilita- } \\
\text { tors that may affect implementation }\end{array}$ & $\begin{array}{l}\text { "For some pharmacies, we send them a } \\
\text { discharge summary in PHARMACe- } \\
\text { HOME and they are overwhelmed and } \\
\text { don't even know where to begin. So we } \\
\text { sit down with our pharmacies to get a } \\
\text { sense of whether they know what to do } \\
\text { with the summary" }\end{array}$ \\
\hline $\begin{array}{l}\text { Tailor strategies to overcome barriers } \\
\text { and honor preferences }\end{array}$ & $\begin{array}{l}\text { Tailor the PHARMACeHOME training to } \\
\text { address barriers and honor community } \\
\text { pharmacy preferences }\end{array}$ & $\begin{array}{l}\text { "How the training is set up depends on } \\
\text { the pharmacy. Some pharmacies prefer } \\
\text { to have just the pharmacist trained on } \\
\text { PHARMACeHOME so that the pharma- } \\
\text { cist can later train other staff while } \\
\text { other pharmacies like to include the } \\
\text { pharmacist and the technician in the } \\
\text { initial training" }\end{array}$ \\
\hline Develop relationships & $\begin{array}{l}\text { Recruit and cultivate relationships with } \\
\text { partners in the NC-CPESN implementa- } \\
\text { tion effort }\end{array}$ & $\begin{array}{l}\text { "We invite them [the pharmacies] to our } \\
\text { offices and then we invite our entire care } \\
\text { management staff to come and meet } \\
\text { with them and talk about their services } \\
\text { and the [clinical] services that they } \\
\text { provide" }\end{array}$ \\
\hline $\begin{array}{l}\text { Develop } \\
\text { educational materials }\end{array}$ & $\begin{array}{l}\text { Develop and format guidelines, man- } \\
\text { uals, toolkits, and other supporting } \\
\text { materials in ways that make it easier for } \\
\text { community pharmacies to learn about } \\
\text { PHARMACeHOME }\end{array}$ & $\begin{array}{l}\text { "To reinforce the messages from the } \\
\text { training that was delivered, we created } \\
\text { how-to guides and step-by-step instruc- } \\
\text { tions about how to document every } \\
\text { piece that needed to be documented so } \\
\text { that the pharmacies could refer back to } \\
\text { it" }\end{array}$ \\
\hline
\end{tabular}


Table 2 (Continued)

\begin{tabular}{|c|c|c|}
\hline Themes & Definition & Illustrative quotation \\
\hline Distribute educational materials & $\begin{array}{l}\text { Distribute PHARMACeHOME training } \\
\text { materials via webinars, in-person } \\
\text { meetings, phone calls, emails, and } \\
\text { onsite visits }\end{array}$ & $\begin{array}{l}\text { "We repeated the webinar multiple } \\
\text { times, probably } 3 \text { or } 4 \text { times at varying } \\
\text { times of day and days of the week to try } \\
\text { to accommodate schedules. We also } \\
\text { recorded them so people could view it } \\
\text { on their own time" }\end{array}$ \\
\hline Make the training more dynamic & $\begin{array}{l}\text { Vary the PHARMACeHOME training } \\
\text { delivery methods to cater to different } \\
\text { learning styles and work contexts, and } \\
\text { to make the training more interactive }\end{array}$ & $\begin{array}{l}\text { "We tried to break it [the webinar] down } \\
\text { into small snippets because we } \\
\text { recognized that pharmacists working in } \\
\text { a store were really busy, and it was hard } \\
\text { for them to carve out an hour and a half } \\
\text { to watch a video" }\end{array}$ \\
\hline $\begin{array}{l}\text { Conduct ongoing training and } \\
\text { consultation }\end{array}$ & $\begin{array}{l}\text { Plan for and conduct training on PHAR- } \\
\text { MACeHOME in an ongoing way, } \\
\text { particularly when new staff members } \\
\text { are hired or when questions about the } \\
\text { software arise }\end{array}$ & $\begin{array}{l}\text { "I go back out and do a separate training } \\
\text { with new staff as they come up to just } \\
\text { show them the system and what they } \\
\text { can do in it" }\end{array}$ \\
\hline $\begin{array}{l}\text { Facilitate relay of clinical data to } \\
\text { pharmacists }\end{array}$ & $\begin{array}{l}\text { Collect new clinical information from } \\
\text { the patient, such as a hospital discharge } \\
\text { summary, and relay it to the pharmacist } \\
\text { via PHARMACeHOME }\end{array}$ & $\begin{array}{l}\text { "We notify the pharmacy that the } \\
\text { patient was discharged from the } \\
\text { hospital with the primary diagnosis, } \\
\text { when the discharge date was, whether } \\
\text { they're going to be care managed, and } \\
\text { then we upload a copy of the after-visit } \\
\text { summary [to PHARMACeHOME]" }\end{array}$ \\
\hline Change record systems & $\begin{array}{l}\text { Change records systems to assist with } \\
\text { documentation of clinical services in } \\
\text { PHARMACeHOME }\end{array}$ & $\begin{array}{l}\text { "They [the pharmacy] developed a } \\
\text { paper form to document the key } \\
\text { comprehensive medication review } \\
\text { components so that they could enter } \\
\text { the data in PHARMACeHOME after } \\
\text { business hours" }\end{array}$ \\
\hline Audit and provide feedback & $\begin{array}{l}\text { Collect and summarize data on the } \\
\text { quality of documentation and give it to } \\
\text { pharmacy staff to improve documenta- } \\
\text { tion quality }\end{array}$ & $\begin{array}{l}\text { "What people interpreted as a compre- } \\
\text { hensive medication review was very } \\
\text { different from how they were } \\
\text { documenting. The importance of } \\
\text { auditing people and giving them } \\
\text { feedback on their documentation in } \\
\text { PHARMACeHOME was going to be key" }\end{array}$ \\
\hline $\begin{array}{l}\text { Develop and implement tools for quality } \\
\text { monitoring }\end{array}$ & $\begin{array}{l}\text { Develop and organize systems and } \\
\text { procedures that monitor documenta- } \\
\text { tion for the purpose of quality assurance } \\
\text { and improvement }\end{array}$ & $\begin{array}{l}\text { "If there was a problem with a phar- } \\
\text { macy, then they [network pharmacists] } \\
\text { would have the audit forms that we } \\
\text { were using and they can provide } \\
\text { individual audits of pharmacies as they } \\
\text { saw fit" }\end{array}$ \\
\hline
\end{tabular}

Abbreviation: NC-CPESN, Community Pharmacy Enhanced Service Network in North Carolina.

templates. Lack of PHARMACeHOME integration with existing pharmacy management systems resulted in double documentation for many pharmacies. Many pharmacies were already using a pharmacy management system to document clinical services and had to also document clinical services in PHARMACeHOME to obtain reimbursement. Double documentation led not only to inefficiency but also incomplete documentation in PHARMACeHOME. Some pharmacies, for example, did not want to enter clinical services into two systems and would only enter the services into their native pharmacy management system. Finally, a lack of standardized templates for documentation within PHARMACeHOME led to uncertainty among pharmacy staff about which aspects of the care plan should be documented. These barriers, however, did not affect enrollment among pharmacies or dropout from the program.

\section{Facilitators to Using PHARMACeHOME}

Some pharmacies were better equipped to use PHARMACeHOME because of their staffing models, employee participation in implementation planning, employees' prior clinical training (e.g., completion of a residency or fellowship for pharmacists, certification for pharmacy technicians) or computer literacy, and leadership support for technology. Some pharmacies devoted staff positions to data entry to reduce documentation burden on pharmacists. Additionally, pharmacies that included employees in implementation planning, 
such as creating a plan for documentation and deciding which staff members will assist with documentation, encountered fewer problems with documentation during CPESN implementation. Pharmacies that had employees with greater clinical training were generally better prepared to interpret and make clinical decisions based on the patient health information provided in PHARMACeHOME (e.g., identifying drug therapy problems from medication lists). Similarly, pharmacy employees that had basic computer literacy (e.g., able to use Microsoft applications such as Outlook and Excel) were able to learn how to navigate PHARMACeHOME more quickly. Finally, pharmacy leaders (e.g., managers, pharmacists, owners) played a key role in supporting PHARMACeHOME use by setting expectations about staff usage of PHARMACeHOME and allocating sufficient staff time for documentation.

\section{Planning Implementation Strategies}

CCNC and research staff used several planning implementation strategies to support pharmacies in their use of PHARMACeHOME including assessing for readiness and identifying barriers and facilitators, tailoring implementation strategies for individual pharmacies, and developing relationships ( - Table 3 ).

When assessing pharmacy readiness, staff described going through a discharge summary (i.e., a care summary for a patient recently discharged from the hospital) with pharmacy staff and asking probing questions about the patients' potential drug therapy problems to assess the clinical knowledge of pharmacy staff. Participants also asked community pharmacy staff to navigate in PHARMACeHOME during the training to assess their computer literacy.

Individual pharmacies required tailored approaches for implementation support given the variation in barriers to implementation and preferences for how training should be delivered. Some of the smaller pharmacies, for example, did not have any pharmacist overlap hours, preventing the pharmacist from being able to leave the dispensing counter for training. In those settings, CCNC network pharmacists delivered training while the pharmacist was also operating the counter to accommodate their schedule. Pharmacies that did not have single sign on capabilities between PHARMACeHOME and their pharmacy management system also needed more technical assistance with how to incorporate documentation into workflow. Some pharmacies also had difficulty with documenting services in real-time due to a slow Internet connection. As a workaround, network pharmacists recommended to these pharmacies to try documenting clinical services after-hours (e.g., after 5 p.m. or on weekends). CCNC network pharmacists also tailored training depending on the pharmacy's preferences for training one staff member versus training all staff members at the same time and for training only pharmacists versus training other pharmacy staff (e.g., pharmacy technicians).

Table 3 Definition and documentation of implementation strategies

\begin{tabular}{|c|}
\hline Implementation strategy category documentation ${ }^{37-39}$ \\
\hline Category: Plan Strategies \\
\hline Name: Assess for readiness and identify barriers and facilitators \\
\hline $\begin{array}{l}\text { Definition: Assess various factors within the pharmacy to determine their readiness for NC-CPESN and barriers } \\
\text { and facilitators that may affect implementation }\end{array}$ \\
\hline Actor: CCNC network pharmacists \\
\hline $\begin{array}{l}\text { Action: During the initial PHARMACeHOME training, network pharmacists went over specific patient cases to assess } \\
\text { pharmacy staff clinical knowledge, had staff members navigate within PHARMACeHOME to assess their computer literacy, } \\
\text { and asked questions about how PHARMACeHOME would be integrated into workflow to identify barriers and facilitators } \\
\text { that might impact their use of PHARMACeHOME }\end{array}$ \\
\hline $\begin{array}{l}\text { Action target: The individual(s) who is identified by the pharmacy as the lead for NC-CPESN activities, which could be the } \\
\text { pharmacy owner, the pharmacist, pharmacy technician, or multiple staff members }\end{array}$ \\
\hline $\begin{array}{l}\text { Temporality: The initial planning meetings between pharmacy staff and CCNC network pharmacists occurred right after the } \\
\text { pharmacy enrolled in NC-CPESN }\end{array}$ \\
\hline $\begin{array}{l}\text { Dose: There is typically one initial planning meeting right after pharmacies enroll in NC-CPESN. However, some pharmacies } \\
\text { elect to have multiple planning meetings with separate groups of staff (e.g., one meeting for pharmacists, one meeting for } \\
\text { pharmacy technicians) }\end{array}$ \\
\hline $\begin{array}{l}\text { Implementation outcome affected: By setting up initial planning meetings, CCNC network pharmacists identified } \\
\text { pharmacies' level of readiness for using PHARMACeHOME as well as their perceived barriers and facilitators }\end{array}$ \\
\hline $\begin{array}{l}\text { Justification: Participants described assessing each pharmacy's readiness during the initial PHARMACeHOME training so } \\
\text { that future training and consultations could be tailored to the needs of individual pharmacies. Participants also delivered } \\
\text { a higher-intensity training and technical assistance for pharmacies with less experience delivering clinical services and } \\
\text { scaled down the training for more experienced pharmacies }\end{array}$ \\
\hline $\begin{array}{l}\text { Lessons learned in practice: Participants recommended being flexible with scheduling to accommodate the busy } \\
\text { schedule of pharmacy staff and to ensure that the training meets the pharmacy's preferences (e.g., preference for } \\
\text { one staff member being trained versus multiple staff) }\end{array}$ \\
\hline
\end{tabular}

Abbreviations: CCNC, Community Care of North Carolina; NC-CPESN, Community Pharmacy Enhanced Service Network in North Carolina. 
Participants explained the importance of developing relationships between the pharmacy, the care managers, and primary care providers to support the exchange of clinical data. Approaches used included organizing health fairs where community pharmacies could introduce their services to primary care providers, care managers, and other community members as well as organizing joint meetings among primary care providers, care managers, and community pharmacies so that they could meet face-to-face and cultivate relationships. Participants reported that in-person meetings among all members of the care team helped to build trust among team members, increasing the likelihood that those providers and care mangers would collaborate with community pharmacies by sharing relevant patient health information.

\section{Educate Implementation Strategies}

CCNC staff members used several approaches to educate pharmacy staff on how to use PHARMACeHOME including developing and distributing educational materials, making training more dynamic, and providing ongoing training and consultation after the initial training was completed ( - Table 4 ).

Educational materials were developed and distributed in various formats, including live webinars, recorded videos, how-to guides with screenshots, and PowerPoint presentations to train community pharmacies on PHARMACeHOME. A variety of formats were chosen to accommodate different learning styles. Additionally, after-meeting summaries were developed following the trainings, which summarized content and pharmacy-specific questions raised during the training.

To distribute the materials, CCNC central office staff organized a webinar series, posted the materials on the PHARMACeHOME Web site, and relied on regional staff to distribute the materials to the pharmacies in person. The webinar and other trainings were hosted on different days of the week and at different times, such as before, during, and after business hours, to reach a larger number of pharmacy staff. CCNC central office staff then developed a repository of materials on PHARMACeHOME so that all educational materials resided in one location that could be accessed by pharmacies and referenced throughout the NC-CPESN program.

Interviewees also shared some of their techniques for making the educational materials and trainings for PHARMACeHOME more dynamic. For example, CCNC staff scoped the webinars as modules to allow pharmacy staff to view the webinar topics in smaller chunks of time to better accommodate the workday schedule of pharmacists. Using real patient cases during training was perceived as useful because it allowed pharmacy staff to identify and document drug therapy problems during training, for which they could later be reimbursed.

Once the initial training was delivered, CCNC staff provided ongoing training and consultation for pharmacies that needed more assistance. Participants described setting up additional trainings when pharmacies asked for assistance with PHARMACeHOME, such as locating patient information

Table 4 Definition and documentation of education strategies

\begin{tabular}{|c|}
\hline Category: Educate strategies \\
\hline Name: Develop educational materials \\
\hline $\begin{array}{l}\text { Definition: Develop webinars, documentation guides, and other educational materials to assist pharmacies with } \\
\text { documentation and how to use PHARMACeHOME }\end{array}$ \\
\hline Actor: CCNC central and regional staff \\
\hline $\begin{array}{l}\text { Action: CCNC staff develops and pilot tests the education materials with the end-users (i.e., community pharmacies), } \\
\text { publish the materials on PHARMACeHOME, and use regional staff to deliver the educational materials in-person }\end{array}$ \\
\hline $\begin{array}{l}\text { Action target: The individual(s) who is identified by the pharmacy as the CPESN lead, which could be the pharmacy owner, } \\
\text { pharmacist, pharmacy technician, or multiple staff members. Participants explained that pharmacies might elect to have } \\
\text { only one individual trained whereas other pharmacies were more inclusive and wanted to include all potential end-users of } \\
\text { PHARMACeHOME in the training }\end{array}$ \\
\hline $\begin{array}{l}\text { Temporality: The educational materials are delivered when a pharmacy first joins CPESN. Pharmacies can request additional } \\
\text { trainings as needed throughout the program. }\end{array}$ \\
\hline $\begin{array}{l}\text { Dose: End-users receive the materials during an initial training and can access the } \\
\text { materials at any time via PHARMACeHOME. Regional staff may provide additional trainings as pharmacies request technical } \\
\text { assistance }\end{array}$ \\
\hline $\begin{array}{l}\text { Implementation outcome affected: The educational materials are intended to encourage documentation of clinical } \\
\text { services in PHARMACeHOME and to improve the quality of documentation }\end{array}$ \\
\hline $\begin{array}{l}\text { Justification: Staff felt that having printed out educational materials with screen shots of PHARMACeHOME would } \\
\text { reinforce the messages shared during the in-person training and serve as a reference if staff had follow-up questions about } \\
\text { PHARMACeHOME }\end{array}$ \\
\hline $\begin{array}{l}\text { Lessons learned in practice: Participants recommended breaking up the content for the educational materials in smaller } \\
\text { modules since pharmacy employees are very busy and might only have time to watch a video clip rather than } \\
\text { a long webinar }\end{array}$ \\
\hline
\end{tabular}

Abbreviations: CCNC, Community Care of North Carolina; CPESN, Community Pharmacy Enhanced Service Network. 
or determining documentation requirements for reimbursement. Additionally, CCNC network pharmacists redelivered in-person, PHARMACeHOME training when community pharmacies hired new staff.

\section{Restructure Implementation Strategies}

CCNC and research team staff also used restructuring strategies to support PHARMACeHOME implementation such as facilitating the relay of clinical data to pharmacists and changing pharmacy record systems ( - Table 5 ).

CCNC network pharmacists prepared summaries for pharmacies that provided health information on any of their patients that were recently released from the hospital. The discharge summaries, when applicable, also included information from the patients' care manager about the social needs of the patient such as availability of transportation and sources of social support. Participants either shared the discharge summaries with community pharmacies via fax or through PHARMACeHOME. To ensure that pharmacies received the discharge summaries, many CCNC network pharmacists conducted follow-up phone calls with pharmacies.

CCNC network pharmacists and research team members developed paper-based record systems and an electronic care plan to assist pharmacies with documentation. Participants developed a short form for staff to document drug therapy problems during the patient encounter or within the prescription processing workflow. Pharmacy staff could use the paper form to support electronic documentation after the patient had left the pharmacy. Network staff also helped pharmacies to develop a paper-based record system to document the key components of the patient encounter. Similarly, the paper-based record was used to support electronic documentation after all aspects of the patient encounter were completed.
CCNC adopted an electronic care plan (Pharmacist eCare Plan) to provide a standardized way for community pharmacies to document clinical services and care plans. ${ }^{41,42}$ The Pharmacist eCare Plan was provided to pharmacies free-ofcharge. The Pharmacist eCare Plan is based on existing HL7 standards, uses value sets from Systematized Nomenclature of Medicine-Clinical Terms (SNOMED CT), and uses Consolidated Clinical Document Architecture (C-CDA) templates for key sections of the care plan (e.g., health concerns, health status, interventions). ${ }^{41}$ Several technology vendors with experience developing community pharmacy applications deployed the Pharmacist eCare Plan. Community pharmacies participating in NC-CPESN were able to select which vendor they wanted to work with. When it was possible, many pharmacies selected the vendor that was the developer of their native pharmacy management system. CCNC worked with each vendor to facilitate pharmacies' adoption and implementation of the Pharmacist eCare Plan.

\section{Quality-Management Implementation Strategies}

Research team members provided pharmacies with qualitymanagement implementation support including audit and feedback on documentation quality and developing and implementing tools for quality monitoring ( - Table 6 ).

Research team members conducted a one-time audit of clinical documentation among a subset of the pharmacies participating in the earliest phase of the program and provided feedback on documentation quality. Audits were used to determine whether initial PHARMACeHOME training efforts were successful. The research team developed clinical documentation audit criteria, which were reviewed by CCNC and other key stakeholders prior to implementation. Since there were a large number of clinical services completed per pharmacy, research team members randomly selected services to audit. Once the

Table 5 Definition and documentation of restructure implementation strategies

\begin{tabular}{|l|}
\hline Category: Restructure strategies \\
\hline Name: Facilitate relay of clinical data to pharmacists \\
\hline Definition: Collect additional clinical information about the patient and relay it to the pharmacist \\
\hline Actor: The pharmacist, the pharmacy technicians, and any other pharmacy staff involved in delivering clinical services \\
\hline $\begin{array}{l}\text { Action: CCNC staff collected information about patients' recent discharge from the hospital including the date of } \\
\text { discharge, the primary diagnosis, and whether the patient was enrolled in care management. CCNC staff then uploaded a } \\
\text { summary of a patients' discharge information to PHARMACeHOME and alerted a staff member of the pharmacy that the } \\
\text { summary had been uploaded by phone or by message in PHARMACeHOME }\end{array}$ \\
\hline $\begin{array}{l}\text { Action target: Any individuals in the pharmacy who participate in delivering clinical services to patients such as pharmacists } \\
\text { and pharmacy technicians }\end{array}$ \\
\hline Temporality: Anytime a CPESN patient is discharged from the hospital \\
\hline Dose: For each patient discharged, one summary is uploaded \\
\hline $\begin{array}{l}\text { Implementation outcome affected: The discharge summaries are created to prompt pharmacy staff to initiate clinical } \\
\text { services, such as a comprehensive medication review, with a patient }\end{array}$ \\
\hline $\begin{array}{l}\text { Justification: Participants explained that discharge summaries provide pharmacy staff } \\
\text { with the information necessary to initiate clinical services }\end{array}$ \\
\hline $\begin{array}{l}\text { Lessons learned in practice: Participants also recommended calling the pharmacy or sending a message via } \\
\text { PHARMACeHOME to ensure a pharmacy staff member is aware that the discharge summary has been uploaded }\end{array}$ \\
\hline
\end{tabular}

Abbreviations: CCNC, Community Care of North Carolina; CPESN, Community Pharmacy Enhanced Service Network. 
Table 6 Definition and documentation of quality-management implementation strategies

\begin{tabular}{|c|}
\hline Category: Quality-management strategies \\
\hline Name: Audit and provide feedback \\
\hline Definition: Collect and summarize data on documentation quality and provide feedback to pharmacy staff \\
\hline Actor: Research team members \\
\hline $\begin{array}{l}\text { Action: The research team members audited randomly selected clinical services (e.g., comprehensive medication review) } \\
\text { from pharmacies participating in the first year of CPESN based on a set of criteria that was reviewed by CCNC and other } \\
\text { key stakeholders. The research team produced summaries of audit findings and heat maps } \\
\text { to share the findings with participating pharmacies. The research team members also organized 30-min phone calls to go } \\
\text { over the audit findings with the pharmacies }\end{array}$ \\
\hline $\begin{array}{l}\text { Action target: Any individuals in the pharmacy who participate in documenting clinical services to patients such as } \\
\text { pharmacists and pharmacy technicians }\end{array}$ \\
\hline Temporality: Each pharmacy went through one audit at the end of the first year of CPESN \\
\hline Dose: One audit was conducted per pharmacy \\
\hline $\begin{array}{l}\text { Implementation outcome affected: The audits were conducted to increase knowledge of the key components of clinical } \\
\text { service documentation and to improve the quality of clinical service documentation in the future }\end{array}$ \\
\hline $\begin{array}{l}\text { Justification: Research team members explained that the quality of clinical service documentation varied widely across } \\
\text { pharmacies and that the audits would help to bring a greater level of standardization to clinical service documentation }\end{array}$ \\
\hline $\begin{array}{l}\text { Lessons learned in practice: Research team members recommended using an easy-to-interpret visual, such as a heat ma } \\
\text { to share the findings of the clinical service audits with pharmacies }\end{array}$ \\
\hline
\end{tabular}

Abbreviations: CCNC, Community Care of North Carolina; CPESN, Community Pharmacy Enhanced Service Network.

audits were conducted, the research team prepared summaries to share back with the pharmacies along with a color-coded result showing the pharmacy's documentation quality score compared against the criteria. In addition to the summaries, the research team delivered feedback to the pharmacies via a 30minute phone call. The feedback was typically shared with the individual responsible for CPESN implementation within the pharmacy (e.g., lead pharmacist, pharmacy manager, pharmacy owner) and the pharmacy decided whether multiple staff members or one staff member participated in the review of the feedback.

Research team members took the criteria used during the audit and developed a checklist for documentation quality that was shared with CCNC network pharmacists and community pharmacy staff. The research team members scheduled meetings with network pharmacists and community pharmacies to go over the checklist and explain its purpose. The intent was to build capacity for future quality audits not dependent on the research team.

\section{Discussion}

In this study, we examined the facilitators and barriers encountered by community pharmacies implementing Web-based, medication management applications and the implementation support they received. Participants used a wide array of planning, education, restructuring, and quality-management implementation strategies to support community pharmacies with PHARMACeHOME implementation. Most of the implementation support was provided by CCNC and research team staff preimplementation or in the early phase of implementation. Although some strategies, such as training, were tailored to the needs of specific pharmacies, many strategies were provided to all pharmacies, with little tailoring to a specific pharmacy's barriers. Below we discuss the implications of these findings and identify areas for future research.

Most of the implementation support was delivered from CCNC and the research team directly to community pharmacies participating in NC-CPESN. Participants did not discuss approaches to technology implementation support that facilitate collaboration among community pharmacies such as peer-to-peer education. ${ }^{37,38}$ A prior study of EHR implementation support found that EHR end-users wanted but lacked a forum to share implementation best practices with peer providers. ${ }^{43}$ Future studies could test implementation strategies that support peer education such as an online forum for sharing best practices, conducting observations, or having higher performing pharmacies share implementation guidance with lower performing pharmacies.

Similar to other interventions, a greater amount of implementation support was provided initially and the ongoing technical assistance was provided on an as-needed basis after PHARMACeHOME implementation. ${ }^{43,44}$ It is possible that some implementation strategies may be needed early in the implementation process, whereas others are needed later to facilitate sustained use of the PHARMACeHOME system. Furthermore, some strategies may only be needed during one implementation stage, whereas others may be needed across multiple stages. For example, available systematic reviews regarding audit and feedback interventions suggest that feedback is most effective when it is delivered frequently. ${ }^{45,46}$ Therefore, audit and feedback may be more effective when delivered at multiple stages of 
implementation. Future research should test how implementation support can be effectively delivered over time to provide ongoing support to pharmacists implementing new information systems such as PHARMACeHOME. ${ }^{37}$

Different types of implementation strategies may be more effective with certain pharmacies depending on the pharmacy type (e.g., Federally Qualified Health Center pharmacy, independent pharmacy), other organizational characteristics (e.g., staff size), or program performance. Our study participants noted that pharmacies with fewer pharmacists overlap hours and pharmacies that did not have single sign on capabilities between PHARMACeHOME and their pharmacy management system required more technical assistance. Future studies could test the effectiveness of providing a higher level of implementation support for high-need pharmacies and a lower level of implementation support for lower-need pharmacies. For example, high-need pharmacies may need more support to build general implementation capacity as compared with project-specific technical assistance. ${ }^{47}$ Researchers may need to adapt metrics to determine how best to differentiate high- versus low-need pharmacies (e.g., organizational readiness to change measures). ${ }^{48}$

Similar to past studies, some community pharmacists had difficulty obtaining patient health information from other health care organizations. ${ }^{49-51}$ Although some causes of provider reluctance cannot be addressed by community pharmacies (e.g., organizational policies about data sharing), our findings suggest planning strategies focusing on developing relationships with providers can mitigate some reluctance to exchanging data. Future studies could examine successful partnerships between community pharmacies and providers to identify strategies that facilitate exchange of health information. Currently, structural barriers limit community pharmacist access to EHRs and HIE programs including differences in state laws, user fees for HIEs, and lack of reimbursement for community pharmacist use of the EHR. ${ }^{18,22,52}$ Future interventions could test financial implementation strategies such as payment models that allow health care organizations to share meaningful use incentives with community pharmacists or support community pharmacist integration into HIEs. ${ }^{53}$

Based on experience with the NC-CPESN program, notable information system gaps became evident, including the inability to integrate pharmacy care plan documentation from PHARMACeHOME within pharmacy management systems. In response, CCNC collaborated with technology vendors to provide participating pharmacies with the Pharmacist eCare Plan. Given its recent implementation, there are many opportunities for future research. Studies, for example, could examine user perspectives on the usability of the Pharmacist eCare Plan and examine whether perspectives about usability vary across vendors. Additionally, future research could examine how organizational characteristics (e.g., staff size, prescription volume) impact the implementation of the Pharmacist eCare Plan and how implementation affects service delivery and patient outcomes.

\section{Limitations}

This study has few limitations. We conducted interviews with individuals delivering implementation support to summarize the implementation strategies used, which may not be sufficient for developing detailed implementation guidance. In addition to interviews, future studies could explore the use of case study methodology to document, in greater detail, the implementation strategies used in a small subset of pharmacies. Additionally, our findings regarding implementation support may not be generalizable to other settings. CCNC has a unique structure for supporting community pharmacies participating in NC-CPESN-including support not only from a central office but also regional staff such as network pharmacists and care managers. ${ }^{6}$ This level of support may not be available in other states, and therefore this intervention may not be replicable in other settings. Further, CCNC network staff has the autonomy to tailor PHARMACeHOME training for the pharmacies in their network-making it difficult to assess which core components of training may be most effective. Future studies could develop a standardized set of implementation strategies to examine which strategies are associated with implementation effectiveness.

\section{Conclusion}

Implementing any new information system requires a significant amount of implementation support to help endusers learn about program features, how to integrate the software into the workflow, and how to optimize the software to improve patient care. This study helps to describe in detail how one statewide network provided implementation support to end-users to overcome barriers associated with implementation. Community pharmacies implementing new medication management applications are likely to encounter similar barriers and need a similar level of implementation support given that community pharmacists typically lack access to clinical data and use pharmacy management systems designed around a dispensing rather than clinical workflow. ${ }^{16,20,21}$ Further research is needed to determine which implementation strategies are most effective, at what time during implementation, and under what conditions.

\section{Clinical Relevance Statement}

Reorienting community pharmacies from a dispensing to population health management focus requires Web-based medication management applications that allow for documentation of clinical services, integration of clinical data, and tracking of patient outcomes. This study provides a description of the barriers and facilitators experienced by community pharmacies implementing a Web-based medication management application and the implementation support provided to help overcome such barriers. This research can be used in the future to develop interventions designed to support community pharmacies implementing new information systems. 


\section{Multiple Choice Question}

When implementing a Web-based medication management application, community pharmacies need which of the following?
a. Provider status
b. Implementation support
c. Cooperative practice agreements
d. Provider EHR access

Correct Answer: The correct answer is option b. Cooperative practice agreements, provider status, and EHR access might serve as facilitators to implementation but implementation support is necessary for the implementation of Web-based medication management applications. End-users need assistance with learning program features and integrating these systems into the workflow.

\section{Note}

The contents of this publication are solely the responsibility of the authors and do not necessarily represent the official views of the U.S. Department of Health and Human Services or any of its agencies.

\section{Protection of Human and Animal Subjects}

The Institutional Review Board of the University of North Carolina at Chapel Hill approved this study (IRB \# 16-0530).

\section{Funding}

The project described was supported by Grant Number 1C1CMS331338 from the Department of Health and Human Services, Centers for Medicare \& Medicaid Services.

\section{Conflict of Interest}

None.

\section{References}

1 Ward BW, Schiller JS, Goodman RA. Multiple chronic conditions among US adults: a 2012 update. Prev Chronic Dis 2014; 11:E62

2 Gerteis J, Izrael D, Deitz D, et al. Multiple Chronic Conditions Chart Book. Rockville, MD2014. Contract No.: AHRQ Publications No, Q14-0038

3 Brown MT, Bussell JK. Medication adherence: WHO cares? Mayo Clin Proc 2011;86(04):304-314

4 DiMatteo MR. Variations in patients' adherence to medical recommendations: a quantitative review of 50 years of research. Med Care 2004;42(03):200-209

5 Frieden TR; Centers for Disease Control and Prevention (CDC). Use of selected clinical preventive services among adults-United States, 2007-2010. MMWR Suppl 2012;61(02):1-2

6 CCNC. Community Pharmacy Enhanced Services Network; 2016. Available at: https://www.communitycarenc.org/population-management/pharmacy/community-pharmacy-enhanced-servicesnetwork-cpesn/. Accessed October 21, 2016

7 Urick B, Brown P, Easter JC. Achieving better quality and lower costs in Medicaid through enhanced pharmacy services. N C Med J 2017;78(03):188-189
8 Smith M, Giuliano MR, Starkowski MP. In Connecticut: improving patient medication management in primary care. Health Aff (Millwood) 2011;30(04):646-654

9 Doucette WR, Rippe JJ, Gaither CA, Kreling DH, Mott DA, Schommer JC. Influences on the frequency and type of community pharmacy services. J Am Pharm Assoc (2003) 2017; 57(01):72-76

10 Van Wijk BL, Klungel OH, Heerdink ER, de Boer A. Effectiveness of interventions by community pharmacists to improve patient adherence to chronic medication: a systematic review. Ann Pharmacother 2005;39(02):319-328

11 Viswanathan M, Kahwati LC, Golin CE, et al. Medication therapy management interventions in outpatient settings: a systematic review and meta-analysis. JAMA Intern Med 2015;175(01): $76-87$

12 Mekonnen AB, McLachlan AJ, Brien JA. Pharmacy-led medication reconciliation programmes at hospital transitions: a systematic review and meta-analysis. J Clin Pharm Ther 2016;41(02):128-144

13 Nazar H, Nazar Z, Portlock J, Todd A, Slight SP. A systematic review of the role of community pharmacies in improving the transition from secondary to primary care. Br J Clin Pharmacol 2015;80(05): 936-948

14 Bailey AM, Wermeling DP. Naloxone for opioid overdose prevention: pharmacists' role in community-based practice settings. Ann Pharmacother 2014;48(05):601-606

15 Blalock SJ, Roberts AW, Lauffenburger JC, Thompson T, O'Connor SK. The effect of community pharmacy-based interventions on patient health outcomes: a systematic review. Med Care Res Rev 2013;70(03):235-266

16 Williams AB, Mertz K, Wilkins TL. Issue Brief: Medication Adherence and Health IT. Washington DC: Office of the National Coordinator for Health Information Technology; 2014

17 Phansalkar S, Her QL, Tucker AD, et al. Impact of incorporating pharmacy claims data into electronic medication reconciliation. Am J Health Syst Pharm 2015;72(03):212-217

18 Gabriel MH, Smith JY, Sow M, Charles D, Joseph S, Wilkins TL. Dispatch from the non-HITECH-incented Health IT world: electronic medication history adoption and utilization. J Am Med Inform Assoc 2016;23(03):562-569

19 Fitzgerald RJ. Medication errors: the importance of an accurate drug history. Br J Clin Pharmacol 2009;67(06):671-675

20 Smith M, Bates DW, Bodenheimer T, Cleary PD. Why pharmacists belong in the medical home. Health Aff (Millwood) 2010;29(05): 906-913

21 Collaborative P. System Vendor Checklist for Pharmacist Clinical Documentation Workflow. Washington, DC2015

22 Hohmeier KC, Spivey CA, Boldin S, Moore TB, Chisholm-Burns M. Implementation of a health information exchange into community pharmacy workflow. J Am Pharm Assoc (2003) 2017;57(05): 608-615

23 Johnson CM, Marcy TR, Harrison DL, Young RE, Stevens EL, Shadid J. Medication reconciliation in a community pharmacy setting. J Am Pharm Assoc (2003) 2010;50(04):523-526

24 Keller ME, Kelling SE, Cornelius DC, Oni HA, Bright DR. Enhancing practice efficiency and patient care by sharing electronic health records. Perspect Health Inf Manag 2015;12:1b

25 Adler-Milstein J, McAfee AP, Bates DW, Jha AK. The state of regional health information organizations: current activities and financing. Health Aff (Millwood) 2008;27(01):w60-w69

26 Held AD, Woodall LJ, Hertig JB. Pharmacists' familiarity, utilization, and beliefs about Health Information Exchange: a survey of pharmacists in an Indiana pharmacy organization. J Am Pharm Assoc (2003) 2014;54(06):625-629

27 Brock KA, Casper KA, Green TR, Pedersen CA. Documentation of patient care services in a community pharmacy setting. J Am Pharm Assoc (2003) 2006;46(03):378-384

28 Guirguis LM, Lee S, Sanghera R. Impact of an interactive workshop on community pharmacists' beliefs toward patient care. Int J Clin Pharm 2012;34(03):460-467 
29 Bright DR, Lengel AJ, Powers MF. Pharmacists' perceptions of barriers to implementing medication therapy management and the role of pharmacy technicians in overcoming the barriers. J Pharm Technol 2009;25(06):361-367

30 Lounsbery JL, Green CG, Bennett MS, Pedersen CA. Evaluation of pharmacists' barriers to the implementation of medication therapy management services.J Am Pharm Assoc (2003) 2009;49(01):51-58

31 Smith MG, Ferreri SP, Brown P, Wines K, Shea CM, Pfeiffenberger $\mathrm{TM}$. Implementing an integrated care management program in community pharmacies: a focus on medication management services. J Am Pharm Assoc (2003) 2017;57(02):229-235

32 Becker C, Bjornson DC, Kuhle JW. Pharmacist care plans and documentation of follow-up before the Iowa Pharmaceutical Case Management program. J Am Pharm Assoc (2003) 2004;44(03):350-357

33 Millonig MK. Mapping the route to medication therapy management documentation and billing standardization and interoperabilility within the health care system: meeting proceedings. J Am Pharmacists Assoc 2009;49(03):372-382

34 Gaskins RE. Innovating Medicaid: the North Carolina experience. N C Med J 2017;78(01):20-24

35 CCNC. PHARMACeHOME; 2017. Available at: http://www.pharmacyhomeproject.com/the-project/hie-challenge-grant-program/pharmacehome. Accessed August 1, 2017

36 Ulin PR, Robinson ET, Tolley EE. Qualitative Methods in Public Health. 1st ed. San Francisco, CA: Josey-Bass; 2004

37 Powell BJ, McMillen JC, Proctor EK, et al. A compilation of strategies for implementing clinical innovations in health and mental health. Med Care Res Rev 2012;69(02):123-157

38 Powell BJ, Waltz TJ, Chinman MJ, et al. A refined compilation of implementation strategies: results from the Expert Recommendations for Implementing Change (ERIC) project. Implement Sci 2015;10:21

39 Proctor EK, Powell BJ, McMillen JC. Implementation strategies: recommendations for specifying and reporting. Implement Sci 2013;8:139

40 Curran GM, Bauer M, Mittman B, Pyne JM, Stetler C. Effectivenessimplementation hybrid designs: combining elements of clinical effectiveness and implementation research to enhance public health impact. Med Care 2012;50(03):217-226

41 NCPDP. PharmacisteCare Plan: Guidance on the Usage of the HL7 CDA Consolidated Templates for Clinical Notes R2.1 Care Plan. Scottsdale, AZ: National Council for Prescription Drug Programs; 2016
42 CPESN. Pharmacist eCare Plan Gains Momentum. Raleigh, NC: Community Pharmacy Enhanced Services Network; 2017. Available at: https://cpesn.com/newsroom/pharmacist-ecare-plan-gains-mome ntum/. Accessed December 21, 2017

43 Boas SJ, Bishop TF, Ryan AM, Shih SC, Casalino LP. Electronic health records and technical assistance to improve quality of primary care: lessons for regional extension centers. Healthc (Amst) 2014; 2(02):103-106

44 Lynch K, Kendall M, Shanks K, et al. The Health IT Regional Extension Center Program: evolution and lessons for health care transformation. Health Serv Res 2014;49(1 Pt 2):421-437

45 Jamtvedt G, Young JM, Kristoffersen DT, O'Brien MA, Oxman AD. Does telling people what they have been doing change what they do? A systematic review of the effects of audit and feedback. Qual Saf Health Care 2006;15(06):433-436

46 Ivers NM, Grimshaw JM, Jamtvedt G, et al. Growing literature, stagnant science? Systematic review, meta-regression and cumulative analysis of audit and feedback interventions in health care. J Gen Intern Med 2014;29(11):1534-1541

47 Wandersman A, Duffy J, Flaspohler P, et al. Bridging the gap between prevention research and practice: the interactive systems framework for dissemination and implementation. Am J Community Psychol 2008;41(3-4):171-181

48 Helfrich CD, Li YF, Sharp ND, Sales AE. Organizational readiness to change assessment (ORCA): development of an instrument based on the Promoting Action on Research in Health Services (PARIHS) framework. Implement Sci 2009;4:38

49 Oladapo AO, Rascati KL. Review of survey articles regarding medication therapy management (MTM) services/programs in the United States. J Pharm Pract 2012;25(04):457-470

50 Snyder ME, Earl TR, Gilchrist S, et al. Collaborative drug therapy management: case studies of three community-based models of care. Prev Chronic Dis 2015;12:E39

51 Law AV, Okamoto MP, Brock K. Ready, willing, and able to provide MTM services? A survey of community pharmacists in the USA. Res Social Adm Pharm 2009;5(04):376-381

52 Hughes CA, Guirguis LM, Wong T, Ng K, Ing L, Fisher K. Influence of pharmacy practice on community pharmacists' integration of medication and lab value information from electronic health records. J Am Pharm Assoc (2003) 2011;51(05):591-598

53 Bonner L. Pharmacists inch closer to accessing EHRs and HIEs. Pharmacy Today 2016;22:44-47 